\title{
Costs and benefits of polygyny in the cichlid Neolamprologus pulcher
}

\author{
JULIE K. DESJARDINS*, JOHN L. FITZPATRICK†, KELLY A. STIVER*, \\ GLEN J. VAN DER KRAAK $\ddagger$ \&IGAL BALSHINE* \\ *Department of Psychology, Neuroscience and Behaviour, McMaster University \\ $\dagger$ Department of Biology, McMaster University \\ $\ddagger$ †Department of Integrative Biology, University of Guelph \\ (Received 15 November 2006; initial acceptance 3 April 2007; \\ final acceptance 21 September 2007; published online 2 April 2008; MS. number: A10625)
}

\begin{abstract}
Polygyny is regarded as a beneficial strategy for males, whereas females mated with polygynous males (males simultaneously paired to more than one female) often suffer a reduction in pair male contributions. This study examined the costs and benefits associated with polygyny in the cooperatively breeding cichlid Neolamprologus pulcher. In this species, males are facultatively polygynous; some males hold only one territory with one breeding female whereas other males hold multiple territories, each with its own breeding female. Polygynous males were larger than monogamous males and body-scraped less, a behaviour often associated with ectoparasite loads. Polygynous males also had larger testes (controlling for body mass) and higher circulating 11-ketotestosterone levels than monogamous males. Paradoxically, monogamous males occupied higher-quality territories with more shelter and fewer predators. Monogamous males also provided more parental care than polygynous males but the number and survival of young did not vary according to male mating behaviour. The results of our study suggest that females trade-off between male genetic quality and resources in N. pulcher. Our results imply that males holding only one territory may provide their mates with significant assets but may not be able to outcompete neighbours for additional breeding positions because of their small body size and possible higher parasite load. The lack of differences between monogamous and polygynous groups in terms of offspring survival (a measure of reproductive success) suggests that there may be few if any fitness consequences of polygynous pairing for females.
\end{abstract}

(C) 2008 The Association for the Study of Animal Behaviour. Published by Elsevier Ltd. All rights reserved.

Keywords: cichlid; hormones; mating systems; Neolamprologus pulcher; parental behaviour

The evolution of polygyny typically is easily explained from the males' perspective because males increase their reproductive success by gaining access to many fertile females (Orians 1969; Trivers 1972; Emlen \& Oring 1977; Hasselquist 1998). It is more difficult to explain why females mate with polygynous (already mated) males because these females often suffer costs from such matings

Correspondence: J. K. Desjardins, Animal Behaviour Group, Department of Psychology, Neuroscience and Behaviour, McMaster University, 1280 Main Street West, Hamilton, ON L8S 4K1, Canada (email: desjarjk@stanford.edu).J. L. Fitzpatrick is at Department of Biology, McMaster University, Hamilton, ON L8S 4K1, Canada. G. J. Van der Kraak is at Department of Integrative Biology, University of Guelph, Guelph, ON N1G 2W1, Canada.
(Verner \& Willson 1966; Westneat 1988; Slagsvold \& Lifjeld 1994; Pribil \& Searcy 2001). In species where care is important for the survival of the young, females in polygynous groups regularly receive less male assistance and often have lower reproductive success than females paired with monogamous males (Slagsvold \& Lifjeld 1994; Eens \& Pinxten 1995; Kempenaers 1995; Czapka \& Johnson 2000). Consequently, it is difficult to explain theoretically why females would mate with polygynous males. In the real world, mating behaviour is not often the choice of only one sex but instead is more likely the outcome of a conflict between the sexes (Davies 1989). Explaining the evolution and maintenance of polygyny in light of sexual conflict is an area of current active research (Rowe et al. 1994; Chapman et al. 2002; Houston et al. 2005; Parker 2006). In this study, we set out to explore correlates 
of polygyny and to identify possible sources of sexual conflict in a cichlid fish.

Several factors have been suggested to select for polygyny (Emlen \& Oring 1977; Searcy \& Yasukawa 1989). Female-biased sex ratios, in which females have few alternative breeding options, have been shown to lead to polygyny (Smith et al. 1982; Kempenaers 1994; Pinxten $\&$ Eens 1997). However, Trivers (1972) argued that a female-biased sex ratio is derived from the mating system and is not a causal factor. Polygyny is also expected to arise when resources and/or females are spatially clustered; when territories can support multiple females, females can be easily monopolized by a single male (Emlen \& Oring 1977). Females also may benefit more from mating with an already mated male if this ensures them access to a high-quality mate or a high-quality territory with many resources (Verner 1964; Verner \& Willson 1966; Orians 1969). In these situations females will often experience a trade-off between the quality of their mate or territory and the amount of paternal care that would be provided (Dyrcz 1986; Webster 1991a, b; Kempenaers 1994; Slagsvold \& Lifjeld 1994).

Degrees of sexual dimorphism in body size and reproductive investment often differ between monogamous and polygynous species. Polygynous species are associated with more extreme sexual size dimorphism and greater male gonadal investment than what is found in closely related monogamous species (Luetenegger 1978; Gage 1994; Fairbairn 1997; Balshine et al. 2001). Also, steroid hormone fluctuations vary with mating systems (Oliveira et al. 2001). Polygynous species, where males provide little to no paternal care and compete to attract females throughout the breeding season, have been shown to maintain high levels of plasma androgens (at or near their physiological maximum) (Wingfield et al. 1990). In contrast, socially monogamous males that provide paternal care maintain low androgen levels (near the breeding baseline) and show dramatic increases in androgens only in the event of sporadic male-male competition (Wingfield et al. 1990). This idea is known as the challenge hypothesis and has received support in many studies of birds (e.g. Ferree et al. 2004; Geslin et al. 2004; Smith et al. 2005) mammals (e.g. Goymann et al. 2003; Muller \& Wrangham 2004) and fish (e.g. Hirschenhauser et al. 2004; Desjardins et al. 2006). However, to date, no study has examined how androgen levels, specifically testosterone (T) and 11-ketotestosterone (11KT; a primary androgen in fish), differ between males and females in species in which males adopt different mating strategies.

In this study we used the mixed mating system found in the cooperatively breeding cichlid fish Neolamprologus pulcher to explore the behavioural and physiological correlates of multiple versus single pair bonds in males. Neolamprologus pulcher is particularly well suited to this investigation since males are either socially monogamous (occupying a single territory containing a breeding female and a series of helpers) or socially polygynous (holding the dominant breeding position in multiple territories, each containing its own breeding female and helpers) (Limberger 1983), and females may choose males based on these territory characteristics. The aims of our study were (1) to investigate the morphological, physiological and behavioural correlates of males and females adopting these two mating options, (2) to characterize the differences in group composition and territory quality between monogamous and polygynous groups and (3) to explore the costs and benefits for females associated with monogamy versus polygyny in an attempt to explain the mixed mating strategy in N. pulcher.

\section{METHODS}

\section{Study Species, Field Site and Behavioural Measures}

Neolamprologus pulcher lives in social groups consisting of a dominant breeding pair and 1-20 other male and female individuals ('helpers') that assist in all aspects of care (Taborsky \& Limberger 1981; Taborsky 1984, 1985; Balshine-Earn et al. 1998; Stiver et al. 2005; Heg et al. 2005). Parental care by breeders and allocare by helpers consist of territory/nest defence, territory/nest maintenance and direct brood care (fanning and cleaning of the eggs and larvae). Such allocare has been shown to enhance the frequency of breeding events, the number of young produced and offspring survival within the group (Taborsky 1984; Balshine et al. 2001; Brouwer et al. 2005). When not providing care, individual $N$. pulcher feed on zooplankton (usually in the water column) and engage in aggressive and nonaggressive social contact with other members of their group and with conspecifics from other groups in their subpopulations.

Our study area in Kasakalawe Bay, Lake Tanganyika (Zambia: $8.5^{\circ} \mathrm{S}, 31.05^{\circ} \mathrm{E}$ ) consists of thousands of groups of fish divided into nine subpopulations. Between 2 February and 28 April 2005 we collected group composition and mating/pairing data from a sample of $254 \mathrm{~N}$. pulcher groups from all nine subpopulations (see Balshine et al. 2001; Stiver et al. 2007). Groups were found at depths of 8.5-12 $\mathrm{m}$ and were observed using SCUBA. Each group's territory was marked with a uniquely labelled rock and group size, and composition was determined in two or three 5-min observational visits. Of the groups observed in our study area, we targeted 59 groups for close behavioural monitoring and sampling. Thirty-eight of the targeted groups were polygynous (a breeding female and her helpers and the polygynous male associated with this group) and 21 were monogamous groups (a breeding pair and their helpers). The numbers of monogamous and polygynous groups studied did not reflect the proportion of monogamous and polygynous groups in the study area (see Results) and did not represent a random sample of the groups in the study area. Polygynous males were males that participated in parental care in multiple groups and polygynous females were female breeders that were assisted in parental care by a polygynous male. A polygynous group refers to one of a polygynous male's territories consisting of one female and her associated helpers. Each individual in each of the 59 groups was reliably identified using a combination of underwater size estimates and specific individual markings including fin clipping and 
nontoxic acrylic paint injection into scale pouches (Balshine-Earn et al. 1998; Stiver et al. 2006). Territory quality was assessed for each of the 59 groups by counting the number of rocks (potential shelters), actual shelters (rocks used and excavated by fish to hide from predators) and number of other territories within a $1-\mathrm{m}$ radius. We also measured the distance to the nearest $N$. pulcher neighbours with a measuring tape. Finally, to assess predation risk as a measure of territory quality, heterospecific/predator scans were performed twice at each territory by identifying and counting the number of heterospecific fish within $5 \mathrm{~m}$ of each territory.

Two 10-min focal watches were conducted on the four largest individuals in each group: the female breeder and the two largest helpers from her group (regardless of sex) as well as the male breeder associated with this group (either monogamous or polygynous). Because we observed the two largest helpers regardless of sex, the number of large adult male and female helpers observed was not equal. One focal watch on each individual was conducted in the morning and the other was conducted in the afternoon to control for diurnal variation in behaviour (Werner et al. 2003). Each focal watch was preceded by a 2-min habituation period. Prior studies using underwater video cameras show that fish behaviour was not significantly altered by the presence of a SCUBA diving observer (S. Balshine, personal observations). Within 12 min of a diver's arrival, the individuals were feeding, socializing and actively defending their territory normally. All behaviours (averaged across the two watches) including feeding, body scraping, territory maintenance, brood chamber visits, aggression (ramming, chasing, biting, mouth fighting, threat displays and puffed throat display), submission (postures and displays) and social interactions (soft touches, follows and parallel swims) were recorded on PVC slates and later transcribed into data sets at the surface (for details of behaviours see Buchner et al. 2004).

We also noted the target of any aggression observed, which individual/species (conspecific or heterospecific) was the recipient of the aggression and whether it was a group member. We used a composite score called 'parental care' of all care behaviours thought to enhance offspring survival including territory defence, territory maintenance and visits to the brood chamber. Social behaviour was also defined as a composite of all within-group nonaggressive behaviours. Within-group aggression was defined as all aggressive behaviours displayed towards one's own group members. These composite scores for care, aggression and social behaviour have been used extensively with this species (Balshine et al. 2001; Bergmüller et al. 2005; Stiver et al. 2005, 2006). As in previous studies, body scraping (when the fish drags the side of its body against a rock or the substrate) was used as a proxy for ectoparasite load (Gunter 1953; Rand \& Wiles 1988; Barber et al. 2000). We also monitored the survival of young in each group by counting free-swimming larvae on the day that they first emerged from the brood chamber and on 4 consecutive days following the day of emergence. (For further details of the study site, field methods and behavioural observations see Balshine-Earn et al. 1998; Balshine et al. 2001; Stiver et al. 2004, 2005, 2006; Fitzpatrick et al. 2006.)

\section{Hormone Sampling}

Once the behavioural observations were complete for a particular group, we collected all of the focal individuals within this group by placing a conical net directly over the territory (Morley \& Balshine 2002). We then injected a small volume $(3-7 \mathrm{ml})$ of quinaldine (2-methylquinoline; $\mathrm{C}_{6} \mathrm{H}_{4} \mathrm{~N}: \mathrm{C}\left(\mathrm{CH}_{3}\right) \mathrm{CH}: \mathrm{CH}$, an anesthetic) into the centre of the territory while the net was in place and collected the temporarily sedated fish. Fish from each group were placed together in individually marked mesh holding cages $(20 \times 20 \times 20 \mathrm{~cm})$ to recover from sedation and were then slowly ( $\sim 20 \mathrm{~min}$ ) brought to the surface (Fitzpatrick et al. 2006). At the surface, individuals were easily identified by a combination of natural and artificial individual markings on each fish, as well as individual size and group information.

Once at the surface of the water, fish were given a lethal dose of benzocaine (ethyl $p$-aminobenzoate, $1.0 \mu \mathrm{g} / \mathrm{ml}$ ). Fish were then sexed by examining the genitalia and measured for standard length (SL) to the nearest millimetre. Body mass was measured to the nearest $0.001 \mathrm{~g}$ and a blood sample was taken by caudal severance. Sex was confirmed by gonadal examination, then the gonads were removed and weighed to the nearest $0.001 \mathrm{~g}$. Relative gonad investment was measured using the gonadosomatic index $(\mathrm{GSI}=($ gonad mass/body mass $) \times 100 \%)$. Blood collected in heparinized microcapillary tubes was spun at 8000 revolutions/min for $10 \mathrm{~min}$ and the separated plasma was removed and stored at $-20^{\circ} \mathrm{C}$ for analysis of $\mathrm{T}$ and $11 \mathrm{KT}$. There was an unavoidable time delay between the initial sedation of the animals and the collection of hormone samples, a common logistical constraint in many field studies. As a result, the levels of androgens measured were probably lower than the absolute levels expected in nonstressed fish. However, all fish, regardless of sex and status, were handled in a similar manner, and we restricted our analysis to the determination of relative differences in androgen levels, rather than absolute amounts. The blood plasma samples were transported back to Canada (McMaster University and Guelph University) at $-4^{\circ} \mathrm{C}$ for hormone assay.

\section{Hormone Assays}

Steroids were extracted from plasma by shaking the aliquots with $5 \mathrm{ml}$ of diethyl ether twice. After freezing the aqueous phase in an acetone and dry ice bath, the organic phase was decanted and dried. The dry extracts were resolubilized in assay buffer and frozen at $-20^{\circ} \mathrm{C}$. Extraction losses were independently monitored, and the mean $\pm \mathrm{SE}$ recovery following a double extraction procedure was $88 \pm 4 \%$ (Desjardins et al. 2006). We used radioimmunoassay to measure $\mathrm{T}$ and $11 \mathrm{KT}$ following McMaster et al. (1995). The reported values are the average concentrations calculated from duplicate aliquots whose values fell within the 5-95\% binding limits of the appropriate standard curve following linearization with a log-logit transformation. Intra-assay coefficients of variation were $5.8-9.3 \%$ for $\mathrm{T}$ and $4.2-8.9 \%$ for $11 \mathrm{KT}$, and thus, did 
not exceed $15 \%$. Assays for $\mathrm{T}$ and $11 \mathrm{KT}$ were validated for $N$. pulcher before the experiment (Desjardins et al. 2006). The variation in sample size for the two androgens in this study reflects the loss of some samples during hormonal assay and the fact that the fish were often simply too small to recover sufficient blood for the analysis of two hormones.

\section{Statistical Analysis}

Statistical analyses were performed using the software JMP 5.1.1 (version 5.1, SAS Institute Inc., Cary, NC, U.S.A.). Data were tested for normality, log-transformed when necessary and analysed with parametric tests. Twotailed tests were used throughout.

To test for the effects of sex and mating system on behaviour, physiology and morphology, we used two-way ANOVAs and post hoc linear contrast analysis. In the event of a significant interaction term in the two-way ANOVAs, linear contrast analysis was performed to interpret main effects (Rosenthal \& Rosnow 1985). Alpha levels were adjusted using Bonferroni corrections to control for multiple comparisons performed on the same data set. To test the numbers of males and females and of adults and subadults against the null expectations of equal numbers, chi-square tests were performed on the counts of adult and subadult fish in each subpopulation. A fish was classified as adult when its standard length fell within the 95\% sex-specific confidence interval of breeding individuals. For males, this size range was 5.1$6.4 \mathrm{~cm}$, and for females, this size range was $4.2-5.6 \mathrm{~cm}$ (Stiver et al. 2004). We used this designation because larger fish, whether they are breeders or helpers, can successfully compete over open breeding positions in the event of a breeder turnover (Balshine-Earn et al. 1998; Stiver et al. 2004; Fitzpatrick et al. 2008). All smaller individuals were classified as subadults. To test for differences in territory quality between monogamous and polygynous groups, $t$ tests were performed. To test for behavioural differences between monogamous and polygynous males, the behaviour of monogamous males on their only territory was compared to the behaviour of polygynous males on all territories that they monopolized. This allowed us to compare the total workload of monogamous males to the total workload of polygynous males. To examine the effect of mating system on fry survival, 20 groups were selected (12 polygynous, 8 monogamous) and these were monitored daily. All fry were counted for 5 consecutive days. We then used repeated measures ANOVAs and appropriate post hoc tests to analyse these data.

\section{Ethical Note}

The data for this study came from 59 groups that represent a tiny proportion of the thousands of groups found in our study area. The groups were collected over a 4-month period and great care was taken not to collect fish from small subpopulations ( $<10$ groups) and to leave neighbouring groups intact to minimize the impact on the subpopulation. Neighbouring fish would colonize emptied positions and territories within a few days. All research described conformed to the protocols approved by the Animal Research Ethics Board of McMaster University and the Canadian Council for Animal Care guidelines. This research was conducted with the permission and cooperation of the Zambian Department of Fisheries.

\section{RESULTS}

\section{Spatial Structure of Monogamous versus Polygynous Groups}

In the 59 groups that were closely monitored for this study, there were 180 adult females and 105 adult males, a sex ratio that differed significantly from equal $\left(\chi_{1}^{2}=11.5, P<0.001\right)$. In contrast, among the subadult population that we sampled, there were 97 females and 106 males. This ratio was not different from an equal number of males and females $\left(\chi_{1}^{2}=0.4, P=0.53\right)$.

In our study area, $N$. pulcher territories are clustered into distinct subpopulations (Taborsky 1984; Stiver et al. 2004, 2007). Within a subpopulation, polygynous territories held by one male were more closely clustered than were monogamous territories (as measured to their nearest neighbours). On average, the distance between territories shared by one male was shorter (mean $92 \pm 7.1 \mathrm{~cm}$ ) than the average distance between a monogamous male and his nearest neighbour (average distance: $204 \pm 10.8 \mathrm{~cm}$; $\left.t_{28}=-4.85, P<0.001\right)$.

Overall, in our study population, $73 \%$ of females were part of a polygynous group whereas the remaining $27 \%$ of females were part of a monogamous group $(N=254$ groups). Polygynous males maintained a mean \pm SE of $2.75 \pm 0.06$ territories (range 2-6 groups). Among the groups closely monitored for this study $(N=59)$, group size (number of individuals in a breeding female's group) did not differ between monogamous female groups $(7.59 \pm 0.28)$ and polygynous female groups $\left(7.61 \pm 0.17 ; t_{28}=0.06, P=0.95\right)$. Contrary to expectations, monogamous groups appeared to occupy betterquality territories containing more rocks (monogamous: $17.6 \pm 1.0$; polygynous: $\left.13.4 \pm 0.7 ; t_{28}=3.46, P<0.001\right)$ and more shelters (monogamous: $5.9 \pm 0.049$; polygynous: $\left.4.6 \pm 0.32 ; t_{28}=2.3, P=0.02\right)$ than polygynous groups. However, there was no difference in the number of neighbouring territories within a 1-m radius for monogamous and polygynous groups $\left(F_{1,61}=1.549, P=0.21\right)$. Monogamous groups also appeared to have fewer predators within $5 \mathrm{~m}$ of their territory (mean $\pm \mathrm{SE}=5.1 \pm 3.5$ ) than polygynous groups (12.2 \pm 1.4$)$; however, this difference was not significant $\left(t_{28}=1.86, P=0.06\right)$.

\section{Morphological and Physiological Characteristics of Individuals in Monogamous versus Polygynous Groups}

Polygynous males were longer (standard length: $F_{1,81}=13.280, P=0.004$; Fig. 1 a, Table 1 ) and heavier (body mass: $F_{1,81}=20.042, P<0.0001$ ) and scraped their 

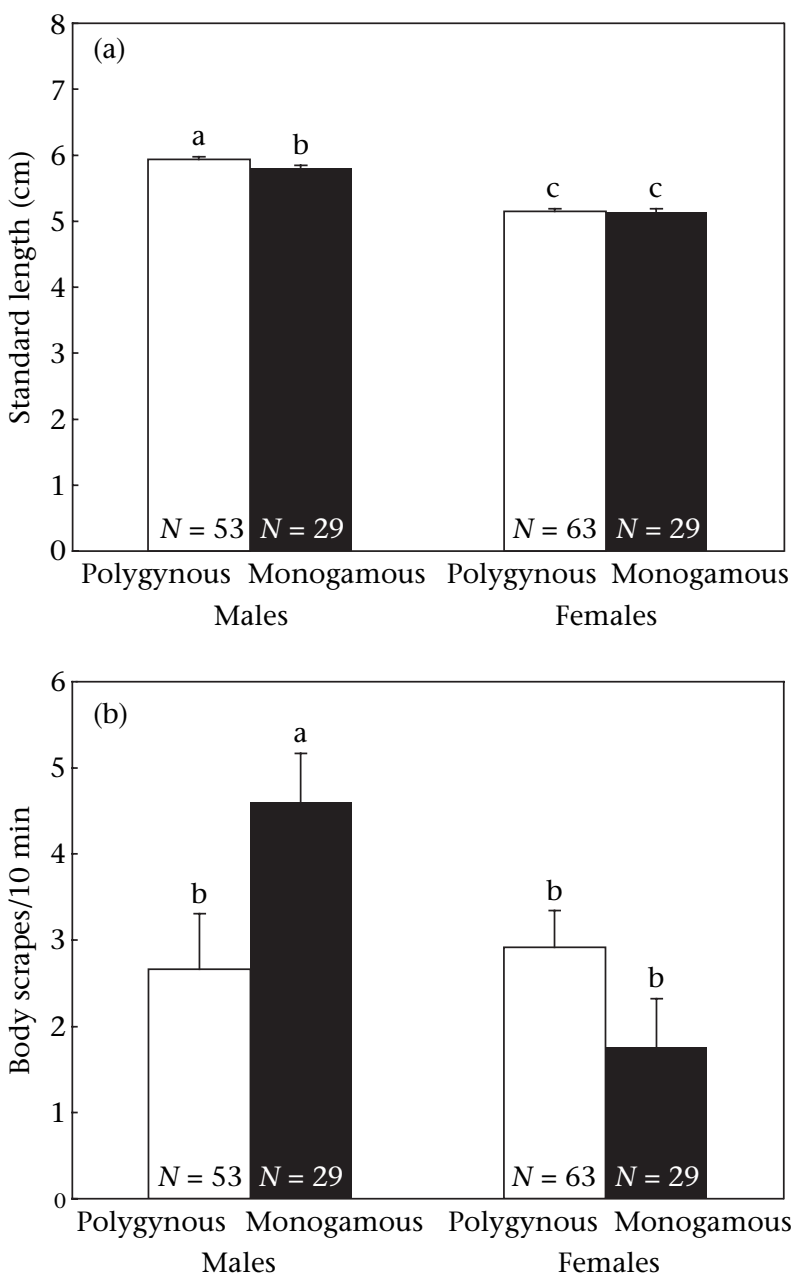

Figure 1. Mean + SE of (a) standard length and (b) number of body scrapes as a function of sex and mating type. Different letters denote significant differences at $\alpha=0.05$.

bodies against rocks less often than did monogamous males $\left(F_{1,81}=10.579, P=0.001\right.$; Fig. $\left.1 b\right)$. Polygynous males had greater relative gonadal investment $\left(F_{1,81}=\right.$ 8.740, $P=0.03$; Fig. $2 \mathrm{a})$ and greater amounts of $11 \mathrm{KT}$ $\left(F_{1,70}=5.733, P=0.02\right.$; Fig. $\left.2 b\right)$ than monogamous males but males did not differ in their $\mathrm{T}$ levels $\left(F_{1,47}=0.023\right.$, $P=0.87$; Fig. 2c). Females paired with monogamous and polygynous males did not differ in body length $\left(F_{1,91}=\right.$ $3.242, P=0.77)$, mass $\left(F_{1,91}=3.322, P=0.72\right)$, or scraping rates $\left(F_{1,91}=2.785, P=0.55\right)$. Monogamous females and polygynous females (controlling for body mass) had similar investment in gonadal tissue $\left(F_{1,91}=0.312\right.$, $P=0.52$ ). In contrast to males, females paired to polygynous and monogamous males did not differ in $11 \mathrm{KT}$ $\left(F_{1,42}=0.014, P=0.91\right)$, but monogamous females had higher T levels than polygynous females $\left(F_{1,27}=5.197\right.$, $P=0.03)$.

\section{Care and Survival of Young in Monogamous versus Polygynous Groups}

Polygynous males spent less time on their territory $\left(F_{1,37}=23.318, \quad P<0.001 ;\right.$ Fig. 3a) and provided less parental care $\left(F_{1,37}=4.514, P=0.03\right.$; Fig. $\left.3 b\right)$ than monogamous males. Polygynous males also fed less than monogamous males $\left(F_{1,37}=19.389, P<0.001\right.$; Fig. 3c). Females paired to monogamous and polygynous males did not differ statistically in any behaviour measured (Fig. 3a). There were no differences between monogamous and polygynous groups in the number of helpers $(\bar{X} \pm \mathrm{SE}: 3.56 \pm 0.27$ versus $\left.3.61 \pm 0.17 ; F_{1,58}=1.089, P=0.29\right)$ or in the size of helpers $\left(4.03 \pm 0.10 \mathrm{~cm}\right.$ versus $4.16 \pm 0.05 \mathrm{~cm} ; \quad F_{1,58}=0.886$, $P=0.54)$. Helpers from polygynous groups did not appear to be compensating for the lack of paternal care; helpers in monogamous and polygynous groups performed allocare equally frequently $\left(F_{1,58}=0.123, P=0.44\right)$, and spent equal amounts of time on territory $\left(F_{1,58}=0.108\right.$, $P=0.45)$.

The mean \pm SE number of fry emerging from polygynous groups $(14.3 \pm 1.6)$ was similar to the mean number of fry emerging from monogamous groups (13.2 \pm 2.7 ; $\left.t_{14}=-1.07, P=0.29\right)$. In all groups, the number of fry decreased over time (repeated measures ANOVA: $F_{4,19}=3.631, P=0.02$; Fig. 4). However, fry survival did not differ between monogamous and polygynous groups (repeated measures ANOVA: $F_{1,19}=0.731, P=0.58$ ). Post hoc tests revealed no differences between the number of fry in monogamous and polygynous groups on any day (all $P>0.53$ ).

\section{DISCUSSION}

A female-biased adult sex ratio and the spatial clustering of females may promote polygyny in our N. pulcher populations. Alternatively, the female-biased sex ratio may be a result of sex-biased dispersal patterns or even the mating system itself (Stiver et al. 2004, 2007) and supports the idea of matrilines (Dierkes et al. 2005). Regardless, given the propensity for males of this species to behave polygynously, it is likely that all $N$. pulcher males 'prefer' to be polygynous and maintain multiple territories, each with its own breeding female, but this preference remains to be tested. In our study populations, socially monogamous males were smaller and scraped their bodies on rocks far more often, a behaviour often suggesting a higher ectoparasite load in other fish species (Gunter 1953; Rand \& Wiles 1988; Barber et al. 2000). Hence, monogamous males may have been of lower quality and thus less capable of defending multiple territories. However, monogamous males fed more, provided more parental care and apparently occupied higher-quality territories.

Our results suggest that female $N$. pulcher that mate with monogamous males may face a trade-off: a smaller male partner of lower quality will provide more paternal care on a safer territory. Females mated with polygynous males also face an apparent trade-off: a higher-quality male partner will provide less parental care and a territory of lower quality. These types of trade-offs, mate quality versus paternal care, have been documented in several species (Dyrcz 1986; Webster 1991a, b; Kempenaers 1994; Slagsvold \& Lifjeld 1994). Females may resolve this apparent trade-off by pairing with a monogamous male but promoting extrapair fertilization by a polygynous 
Table 1. Results of two-way ANOVAs with the overall model results, the main effects (sex and mating type) and the interaction statistics for body morphology, physiology and behaviour

\begin{tabular}{|c|c|c|c|c|}
\hline \multirow[b]{2}{*}{ Variable } & \multirow[b]{2}{*}{ Overall model } & \multicolumn{2}{|c|}{ Main effect } & \multirow[b]{2}{*}{ Interaction? } \\
\hline & & Sex & Mating type & \\
\hline Body length (SL, cm) & $\begin{array}{l}F_{3,104}=72.291 \\
P<0.001\end{array}$ & $\begin{array}{l}F_{1,104}=195.708 \\
P<0.001\end{array}$ & $\begin{array}{l}F_{1,104}=15.156 \\
P<0.001\end{array}$ & No \\
\hline Body mass (g) & $\begin{array}{l}F_{3,104}=119.602 \\
P<0.001\end{array}$ & $\begin{array}{l}F_{1,104}=325.211 \\
P<0.001\end{array}$ & $\begin{array}{l}F_{1,104}=20.471 \\
P<0.001\end{array}$ & No \\
\hline Body scrapes (per $10 \mathrm{~min}$ ) & $\begin{array}{l}F_{3,104}=5.288 \\
P=0.002\end{array}$ & $\begin{array}{l}F_{1,104}=4.214 \\
P=0.04\end{array}$ & $\begin{array}{l}F_{1,104}=1.575 \\
P=0.21\end{array}$ & Yes \\
\hline Gonadal somatic index & $\begin{array}{l}F_{3,103}=6.856 \\
P=0.0003\end{array}$ & $\begin{array}{l}F_{1,103}=18.135 \\
P<0.001\end{array}$ & $\begin{array}{l}F_{1,103}=1.425 \\
P=0.24\end{array}$ & No \\
\hline 11-Ketotestosterone (ng/ml) & $\begin{array}{l}F_{3,63}=14.139 \\
P<0.001\end{array}$ & $\begin{array}{l}F_{1,63}=34.668 \\
P<0.001\end{array}$ & $\begin{array}{l}F_{1,63}=1.826 \\
P=0.18\end{array}$ & No \\
\hline Testosterone $(\mathrm{ng} / \mathrm{ml})$ & $\begin{array}{l}F_{3,45}=2.190 \\
P=0.10\end{array}$ & $\begin{array}{l}F_{1,45}=1.057 \\
P=0.30\end{array}$ & $\begin{array}{l}F_{1,45}=3.696 \\
P=0.06\end{array}$ & Yes \\
\hline Parental care (per $10 \mathrm{~min}$ ) & $\begin{array}{l}F_{3,104}=4.162 \\
P=0.008\end{array}$ & $\begin{array}{l}F_{1,104}=5.226 \\
P=0.02\end{array}$ & $\begin{array}{l}F_{1,104}=7.800 \\
P=0.006\end{array}$ & No \\
\hline Allocare (per $10 \mathrm{~min}$ ) & $\begin{array}{l}F_{3,313}=0.91 \\
P=0.44\end{array}$ & $\begin{array}{l}F_{1.313}=1.13 \\
P=0.29\end{array}$ & $\begin{array}{l}F_{1.313}=0.42 \\
P=0.52\end{array}$ & No \\
\hline Time on territory (per $10 \mathrm{~min}$ ) & $\begin{array}{l}F_{3,104}=26.373 \\
P<0.001\end{array}$ & $\begin{array}{l}F_{1,104}=47.25 \\
P<0.001\end{array}$ & $\begin{array}{l}F_{1,104}=21.962 \\
P<0.001\end{array}$ & Yes \\
\hline Feeding (per $10 \mathrm{~min}$ ) & $\begin{array}{l}F_{3,104}=9.085 \\
P<0.001\end{array}$ & $\begin{array}{l}F_{1,104}=4.992 \\
P=0.03\end{array}$ & $\begin{array}{l}F_{1,104}=19.178 \\
P<0.001\end{array}$ & Yes \\
\hline
\end{tabular}

Parental care was calculated as a composite score of all territory maintenance, direct brood care and territory defence behaviours displayed by the breeding pair. Allocare was calculated as the same composite score of behaviours displayed by the helpers.

high-quality neighbouring male. Although this suggestion remains to be tested, there were no obvious differences between females that paired with monogamous and polygynous males in our study.

Polygynous females did not provide more care for offspring than monogamous females. It is possible that polygynous females received more assistance from their helpers, as is the case in the many birds (Brown 1987; Emlen 1991; Komdeur 1994; Hatchwell \& Russell 1996; Wright 1997; Hatchwell 1999). Our results suggest that this was not the case; monogamous and polygynous groups were of equal size with a similar number of helpers, and helpers in both types of groups provided similar levels of allocare. Interestingly, our measures of offspring survival did not vary between monogamous and polygynous groups. It is possible that survival differences occurred in the brood chamber before the start of our monitoring period. In addition, both the small number of groups monitored and the short monitoring duration suggest the need for further work to examine the long-term fitness consequences in terms of young survival in relation to male pairing behaviour. None the less, our results suggest that the benefits to females of obtaining higher-quality mates, better care or better territories do not necessarily translate into increased reproductive success. If this is indeed the case, being part of a monogamous or a polygynous group may be of little consequence to females; females may even tolerate polygyny especially if any additional breeding females within a harem are close relatives (Emlen 1995; Pen \& Kerth 2005). We are currently investigating whether females are maximizing their inclusive fitness by sharing reproduction with close kin. Finally, females may have little choice in mates and are forced to accept either a polygynous or monogamous male because of the severely limited breeding opportunities available to them (Stiver et al. 2006).

Polygynous males had significantly higher gonadal investment (controlling for body size) and levels of the androgen $11 \mathrm{KT}$ than monogamous males. This finding is not surprising given that polygynous males have access to multiple females and probably fertilize more eggs than monogamous males. The production of $11 \mathrm{KT}$ has been linked to spermatogenesis and the expression of secondary sexual characteristics in many fish (reviewed by Borg 1994). Surprisingly, in this study there were no overall differences in $\mathrm{T}$ between males and females. Using monogamous groups in the field and in the laboratory, our previous research revealed much higher levels of $\mathrm{T}$ in females than in males (Desjardins et al. 2006; Aubin-Horth et al. 2007). This pattern for monogamous groups was confirmed in this study; the high levels of T drove the previously reported differences in $\mathrm{T}$ between males and females in monogamous groups. But why would monogamous females have higher levels of $\mathrm{T}$ than polygynous females? In this study, monogamous females provided slightly more parental care than polygynous females. $\mathrm{T}$ levels may be related to the level of parental care provided by the breeding female (Desjardins et al. 2008). To answer this question more completely, further investigation is required.

Females paired with polygynous males may experience other costs that we did not measure, such as reduced longevity and lower lifetime reproductive success. Longterm monitoring of wild populations is needed to investigate this suggestion. Future experiments designed to manipulate ecological conditions such as the number of 

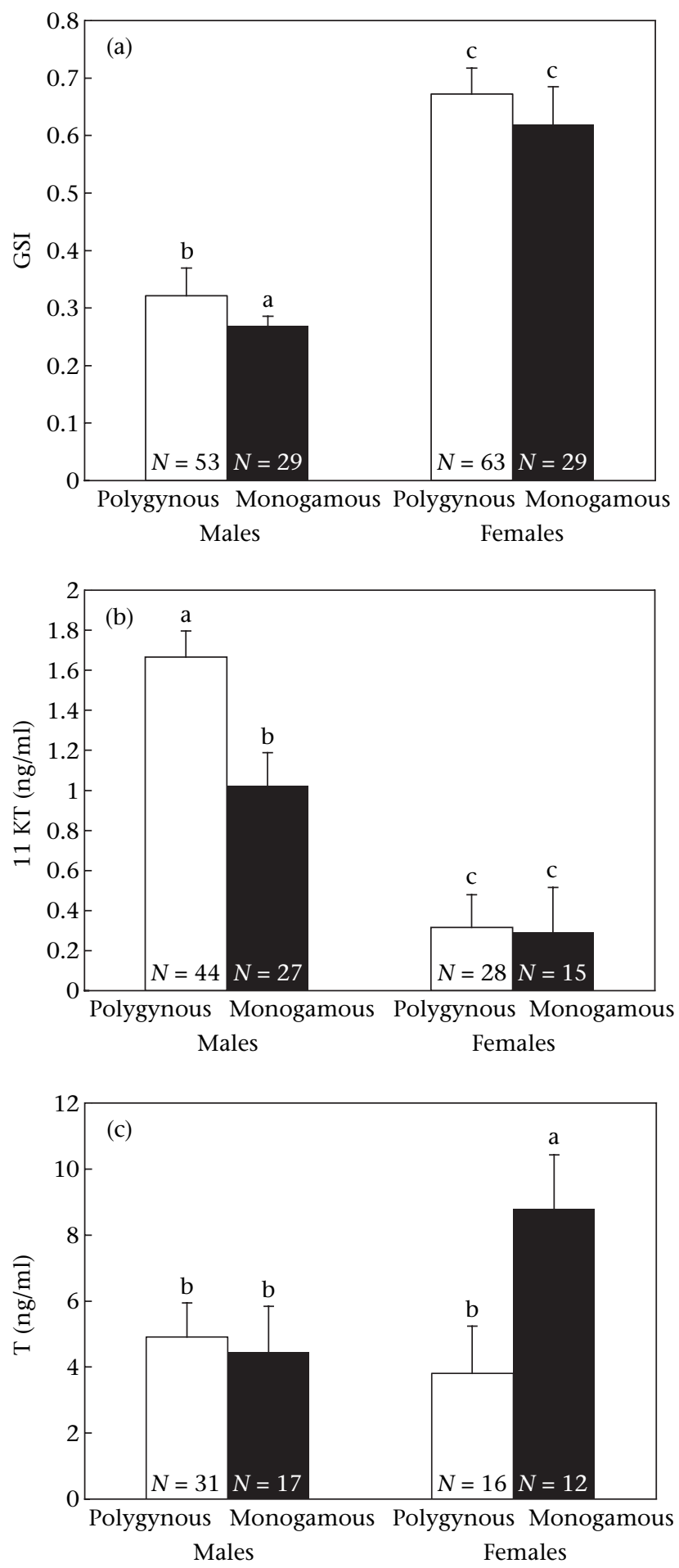

Figure 2. Mean + SE of (a) GSI, (b) $11 \mathrm{KT}$ and (c) T as a function of sex and mating type. Different letters denote significant differences at $\alpha=0.05$.

predators or the amount of food available could reveal the subtle fitness consequences for males and females in monogamous and polygynous groups. In addition, experimental manipulations of androgens in monogamous and polygynous individuals of both sexes would clarify whether androgens regulate the ability of males to be
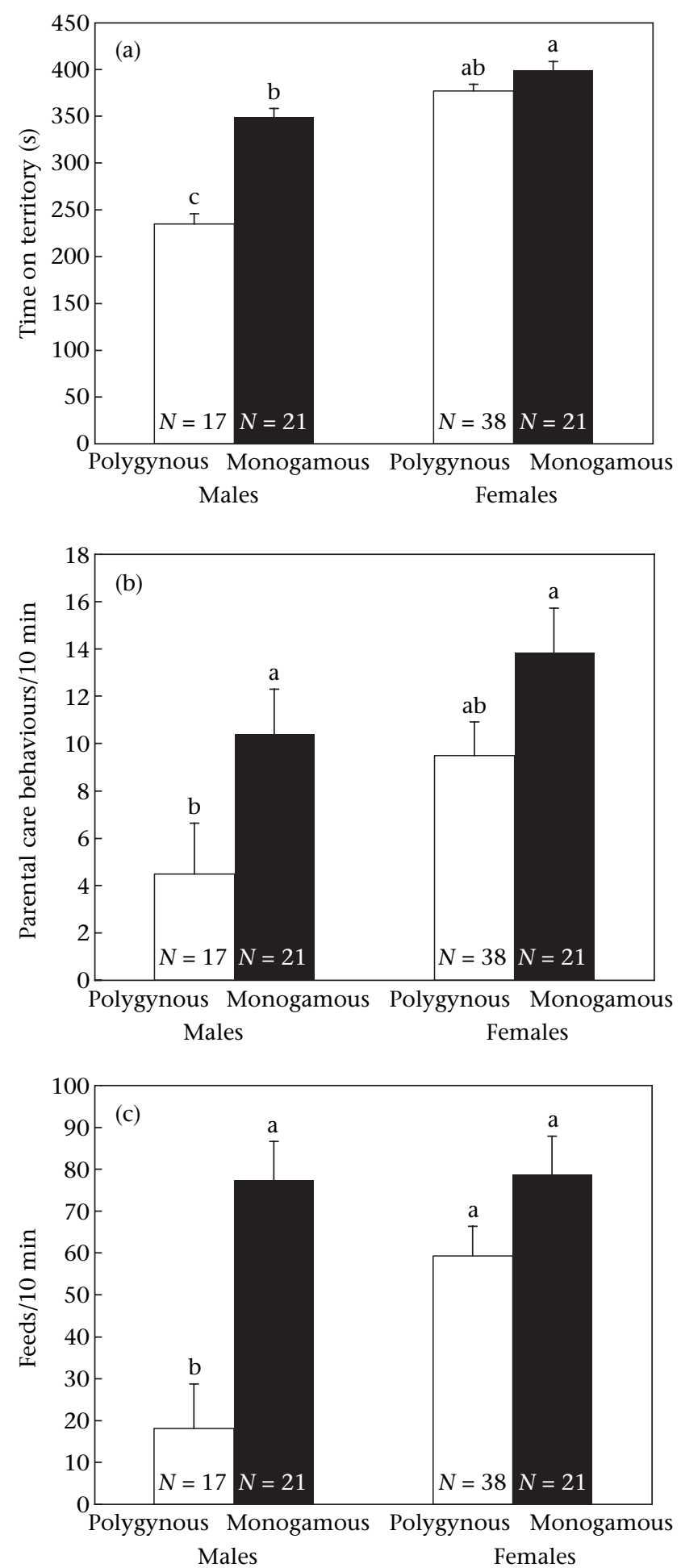

Figure 3. Mean + SE rate of (a) time on territory ( $\max =600 \mathrm{~s}$ ), (b) parental care and (c) feeding as a function of sex and mating type. Different letters denote significant differences at $\alpha=0.05$.

polygynous and the ability of females to provide adequate parental care. Ultimately, our data suggest that the mixed mating system in $N$. pulcher may result from differential male competitive ability and that females may not suffer high reproductive costs of polygyny. 




Figure 4. Offspring survival over a 5-day period. The number of young in each group (12 polygynous, 8 monogamous) was counted on the day that young emerged from the brood chamber and for the 4 days following emergence.

\section{Acknowledgments}

This research was conducted with the kind permission of Dr H. Phiri, Dr. Ngalada and Dr C. Kapasa of the Zambian Ministry of Agriculture, Food and Fisheries and the Government of Zambia. We are grateful to the staff of the Lake Tanganyika Research Unit for their great help and cooperation in this study, particularly H. Phiri, D. Sinyinza and R. Shapolla. We thank S. Marsh-Rollo, two anonymous referees and A. Kodric-Brown for their helpful comments on the manuscript. The work conformed to the guidelines of the Canadian Council on Animal care and was approved by the Animal Research and Ethics Board at McMaster University (Animal Utilization Protocol no. 03-09-54). This study was supported by funding from the Natural Sciences and Engineering Research Council of Canada in the form of Discovery and Equipment grants to S.B. and G.V.D.K. and scholarships to J.K.D. and J.L.F. Funding was also provided by the Canadian Foundation for Innovation and the Ontario Innovation Trust to S.B.

\section{References}

Aubin-Horth, N., Desjardins, J. K., Martei, Y., Balshine, S. \& Hofmann, H. A. 2007. Masculinized dominant females in a cooperatively breeding species. Molecular Ecology, 16, 1349-1358.

Balshine-Earn, S., Neat, F. C., Reid, H. \& Taborsky, M. 1998. Paying to stay or paying to breed? Field evidence for direct benefits of helping behaviour in a cooperatively breeding fish. Behavioral Ecology, 9, 432-438.

Balshine, S., Leach, B., Neat, F., Reid, H., Taborsky, M. \& Werner, N. 2001. Correlates of group size in a cooperatively breeding cichlid fish (Neolamprologus pulcher). Behavioral Ecology and Sociobiology, 50, 134-140.

Barber, I., Hoare, D. \& Krause, J. 2000. Effects of parasites on fish behaviour: a review and evolutionary perspective. Reviews in Fish Biology and Fisheries, 10, 131-165.

Bergmüller, R., Heg, D. \& Taborsky, M. 2005. Helpers in a cooperatively breeding cichlid stay and pay or disperse and breed, depending on ecological constraints. Proceedings of the Royal Society of London, Series B, 272, 325-331.
Borg, B. 1994. Androgens in teleost fishes. Comparative Biochemistry and Physiology, 109C, 219-245.

Brouwer, L., Heg, D. \& Taborsky, M. 2005. Experimental evidence for helper effects in a cooperatively breeding cichlid. Behavioral Ecology, 16, 667-673.

Brown, J. L. 1987. Helping and Communal Breeding in Birds. Princeton, New Jersey: Princeton University Press.

Buchner, A. S., Sloman, K. A. \& Balshine, S. 2004. The physiological effects of social status in the cooperatively breeding cichlid Neolamprologus pulcher. Journal of Fish Biology, 65, 1080-1095.

Chapman, T., Arnqvist, G., Bangham, J. \& Rowe, L. 2002. Sexual conflict. Trends in Ecology \& Evolution, 18, 41-46.

Czapka, S. J. \& Johnson, L. S. 2000. Consequences of mate sharing for first-mated females in a polygynous songbird, the house wren. Wilson Bulletin, 112, 72-81.

Davies, N. B. 1989. Sexual conflict and the polygamy threshold. Animal Behaviour, 38, 226-234.

Dierkes, P., Heg, D., Taborsky, M., Skubic, E. \& Achmann, R. 2005. Genetic relatedness in groups is sex specific and declines with age of helpers in a cooperatively breeding cichlid. Ecology Letters, 8, 968-975.

Desjardins, J. K., Hazelden, M. R., Van der Kraak, G. J. \& Balshine, S. 2006. Male and female cooperatively breeding fish provide support for the 'challenge hypothesis'. Behavioral Ecology, 17, 149-154.

Desjardins, J. K., Stiver, K. A., Fitzpatrick, J. L., Milligan, N., Van der Kraak, G. J. \& Balshine, S. 2008. Sex and status in a cooperative breeding fish: behavior and androgens. Behavioral Ecology and Sociobiology, 62, 785-794.

Dyrcz, A. 1986. Factors affecting facultative polygyny and breeding results in the great reed warbler Acrocephalus arundinaceus. Journal of Ornithology, 127, 447-461.

Eens, M. \& Pinxten, R. 1995. Inter-sexual conflicts over copulations in the European starling: evidence for the female mate-guarding hypothesis. Behavioral Ecology and Sociobiology, 36, 71-81.

Emlen, S. T. 1991. Evolution of cooperative breeding in birds and mammals. In: Behavioural Ecology: an Evolutionary Approach (Ed. by J. R. Krebs \& N. B. Davies), pp. 301-337. Oxford: Blackwell Scientific.

Emlen, S. T. 1995. An evolutionary theory of the family. Proceedings of the National Academy of Sciences, U.S.A., 92, 8092-8099.

Emlen, S. T. \& Oring, L. W. 1977. Ecology, sexual selection, and the evolution of mating systems. Science, 197, 215-223.

Fairbairn, D. J. 1997. Allometry for sexual size dimorphism: pattern and process in the coevolution of body size in males and females. Annual Review of Ecology and Systematics, 28, 659-687.

Ferree, E. D., Wikelski, M. C. \& Anderson, D. J. 2004. Hormonal correlates of siblicide in Nazca boobies: support for the challenge hypothesis. Hormones and Behavior, 46, 655-662.

Fitzpatrick, J. L., Desjardins, J. K., Stiver, K. A., Montgomerie, R. \& Balshine, S. 2006. Male reproductive suppression in the cooperatively breeding fish Neolamprologus pulcher. Behavioral Ecology, 17, 25-33.

Fitzpatrick, J. L., Desjardins, J. K., Milligan, N., Stiver, K. A., Montgomerie, R. L. \& Balshine, S. 2008. Female-mediated causes and consequences of status change in a social fish. Proceedings of the Royal Society of London, Series B, 275, 929-936.

Gage, M. J. G. 1994. Associations between body size, mating pattern, testes size and sperm lengths across butterflies. Proceedings of the Royal Society of London, Series B, 258, 247-254.

Geslin, T., Chastel, O. \& Eybert, M.-C. 2004. Sex-specific patterns in body condition and testosterone level changes in a territorial migratory bird: the bluethroat Luscinia svecica. Ibis, 146, 632-641.

Goymann, W., East, M. L. \& Hofer, H. 2003. Defense of females, but not social status, predicts plasma androgen levels in male 
spotted hyenas. Physiological and Biochemical Zoology, 76, 586593.

Gunter, G. 1953. Observations on fish turning flips over a line. Copeia, 1953, 188-190.

Hasselquist, D. 1998. Polygyny in great reed warblers: a long-term study of factors contributing to male fitness. Ecology, 79, 23762390.

Hatchwell, B. J. 1999. Investment strategies of breeders in avian cooperative breeding systems. American Naturalist, 154, 205-219.

Hatchwell, B. J. \& Russell, A. F. 1996. Provisioning rules in cooperatively breeding long-tailed tits Aegithalos caudatus: an experimental study. Proceedings of the Royal Society of London, Series B, 263, 83-88.

Heg, D., Brouwer, L., Bachar, Z. \& Taborsky, M. 2005. Large group size yields group stability in the cooperatively breeding cichlid Neolamprologus pulcher. Behaviour, 142, 1615-1641.

Hirschenhauser, K., Taborsky, M., Oliveira, T., Canario, A. V. M. \& Oliveira, R. F. 2004. A test of the 'challenge hypothesis' in cichlid fish: simulated partner and territory intruder experiments. Animal Behaviour, 68, 741-750.

Houston, A. I., Székely, T. \& McNamara, J. M. 2005. Conflict between parents over care. Trends in Ecology \& Evolution, 20, 33-39.

Kempenaers, B. 1994. Polygyny in the blue tit: unbalanced sex ratio and female aggression restrict male choice. Animal Behaviour, 47, 943-957.

Kempenaers, B. 1995. Polygyny in the blue tit: intra- and inter-sexual conflicts. Animal Behaviour, 49, 1047-1064.

Komdeur, J. 1994. The effect of kinship on helping in the cooperative breeding Seychelles warbler (Acrocephalus sechellensis). Proceedings of the Royal Society of London, Series B, 256, 47-52.

Limberger, D. 1983. Pairs and harems in a cichlid fish. Lamprologus brichardi. Zeitschrift für Tierpsychologie, 62, 115-144.

Luetenegger, W. 1978. Scaling of sexual dimorphism in body size and breeding system in primates. Nature, 272, 610-611.

McMaster, M. E., Munkittrick, K. R., Jardine, J. J., Robinson, R. D. \& Van der Kraak, G. J. 1995. Protocol for measuring in vitro steroid production by fish gonadal tissue. Canadian Technical Report of Fisheries and Aquatic Sciences, 1961, 1-18.

Morley, J. I. \& Balshine, S. 2002. Faithful fish: territory and mate defence favour monogamy in African cichlid fish. Behavioral Ecology and Sociobiology, 52, 326-331.

Muller, M. N. \& Wrangham, R. W. 2004. Dominance, aggression and testosterone in wild chimpanzees: a test of the challenge hypothesis. Animal Behaviour, 67, 113-123.

Oliveira, R. F., Almada, V. C., Gonçalves, E. J., Forsgren, E. \& Canario, A. V. M. 2001. Androgen levels and social interactions in breeding males of the peacock blenny. Journal of Fish Biology, 58, 897-908.

Orians, G. H. 1969. On the evolution of mating systems in birds and mammals. American Naturalist, 103, 589-603.

Parker, G. A. 2006. Sexual conflict over mating and fertilization: an overview. Philosophical Transactions of the Royal Society of London, Series B, 361, 235-259.

Pen, I. \& Kerth, G. 2005. Mate choice: female relatives share sexual partners in bats. Current Biology, 15, 927-929.

Pinxten, R. \& Eens, M. 1997. Copulations and mate guarding patterns in polygynous male starlings. Animal Behaviour, 54, 45-58.

Pribil, S. \& Searcy, W. A. 2001. Experimental confirmation of the polygyny threshold model for red-winged blackbirds. Proceedings of the Royal Society of London, Series B, 268, 1643-1646.

Rand, T. G. \& Wiles, M. 1988. Bacterial involvement in a saddleback disease of the reef silverside, Atherina harringtonensis Goode (Pisces: Atherinidae) from Bermudan waters. Journal of Fish Biology, 32, 805-816.
Rosenthal, R. \& Rosnow, R. L. 1985. Contrast Analysis: Focused Comparisons in the Analysis of Variance. Cambridge: Cambridge University Press.

Rowe, L., Arnqvist, G., Sih, A. \& Krupa, J. J. 1994. Sexual conflict and the evolutionary ecology of mating patterns: water striders as a model system. Trends in Ecology \& Evolution, 9, 289-293.

Searcy, W. A. \& Yasukawa, K. 1989. Alternative models of territorial polygyny in birds. American Naturalist, 134, 323-343.

Slagsvold, T. \& Lifjeld, J. T. 1994. Polygyny in birds: the role of competition between females for male parental care. American Naturalist, 143, 59-94.

Smith, J. M. N., Yom-Tov, Y. \& Moses, R. 1982. Polygyny, male parental care and sex ratio in song sparrows: an experimental study. Auk, 99, 555-564.

Smith, L. C., Raouf, S. A., Brown, M. B., Wingfield, J. C. \& Brown, C. R. 2005. Testosterone and group size in cliff swallows: testing the "challenge hypothesis" in a colonial bird. Hormones and Behavior, 47, 76-83.

Stiver, K. A., Dierkes, P., Taborsky, M. \& Balshine, S. 2004. Dispersal patterns and status changes in a cooperatively breeding cichlid, Neolamprologus pulcher: evidence from microsatellite analyses and behavioural observations. Journal of Fish Biology, 65, 91-105.

Stiver, K. A., Dierkes, P., Taborsky, M., Gibbs, H. L. \& Balshine, S. 2005. Relatedness and helping in fish: examining the theoretical predictions. Proceedings of the Royal Society of London, Series B, 272, 1593-1599.

Stiver, K. A., Fitzpatrick, J. L., Desjardins, J. K. \& Balshine, S. 2006. Sex differences in rates of territory joining and inheritance in a cooperatively breeding cichlid fish. Animal Behaviour, 71, 449-456.

Stiver, K. A., Desjardins, J. K., Fitzpatrick, J. L., Neff, B., Quinn, J. S. \& Balshine, S. 2007. Evidence for size and sex-specific dispersal in a cooperatively breeding cichlid fish. Molecular Ecology, 16, 2974-2984.

Taborsky, M. 1984. Broodcare helpers in the cichlid fish, Lamprologus brichardi: their costs and benefits. Animal Behaviour, 32, 1236-1252.

Taborsky, M. 1985. Breeder-helper conflict in a cichlid fish with broodcare helpers: an experimental analysis. Behaviour, 95, 45-75.

Taborsky, M. \& Limberger, D. 1981. Helpers in fish. Behavioral Ecology and Sociobiology, 8, 143-145.

Trivers, R. L. 1972. Parental investment and sexual selection. In: Sexual Selection and the Descent of Man (Ed. by B. Campbell), pp. 136-179. Chicago: Aldine.

Verner, J. 1964. Evolution of polygamy in the long-billed marsh wren. Evolution, 18, 252-261.

Verner, J. \& Willson, M. F. 1966. The influence of habitats on mating systems of North American passerine birds. Ecology, 47, 143-147.

Webster, M. S. 1991a. Male parental care and polygyny in birds. American Naturalist, 137, 274-280.

Webster, M. S. 1991b. Sexual dimorphism, mating system and body size in New World blackbirds (Icterinae). Evolution, 46, 1621-1641.

Werner, N. Y., Balshine, S., Leach, B. \& Lotem, A. 2003. Helping opportunities and space segregation in cooperatively breeding cichlids. Behavioral Ecology, 14, 749-756.

Westneat, D. F. 1988. Male parental care and extrapair copulations in the indigo bunting. Auk, 105, 149-160.

Wingfield, J. C., Hegner, R. E., Dufty, A. M., Jr \& Ball, G. F. 1990. The "challenge hypothesis": theoretical implications for patterns of testosterone secretion, mating systems and breeding strategies. American Naturalist, 136, 829-846.

Wright, J. 1997. Helpers-at-the-nest in Arabian babblers: signalling social status or sensible investment in chicks? Animal Behaviour, 54, 1439-1448. 